\title{
Un varón con una alopecia frontal fibrosante: ¿una entidad únicamente femenina?
}

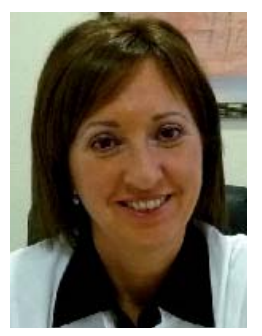

María R. Navarro Belmonte Unidad de Tricología. Centro Dermatológico Estético. Alicante.

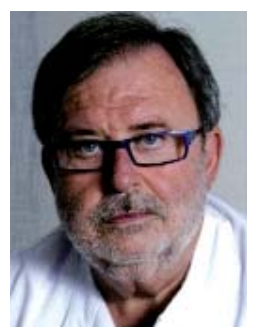

Manuel Asín Llorca Dermatólogo. Director de la Cátedra de Dermocosmética. Universidad Miguel Hernández. Alicante.

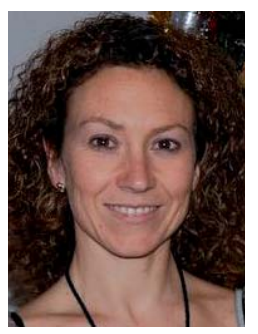

Elena Gonzalo Sierra

Médico adjunto de Anatomía Patológica.

Hospital Infanta Cristina. Madrid.

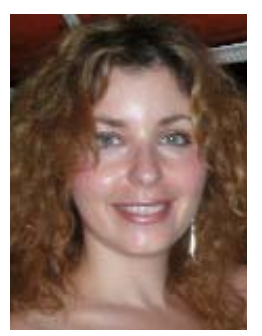

Elena González-Guerra Médico adjunto de Dermatología. Hospital Infanta Cristina. Madrid.
Mi paciente es un varón con una alopecia frontal fibrosante. Este diagnóstico me ha resultado sorprendente porque esta entidad se ha considerado hasta ahora como un proceso típicamente femenino ${ }^{1}$.

Este paciente, de 57 años, presentaba desde hacía 2 años una retrocesión de la línea frontotemporal de implantación del cabello, con pérdida difusa del pelo en ambas cejas. Había sido diagnosticado de alopecia areata ofiásica y los tratamientos, básicamente corticoides tópicos, a los que había sido sometido habían resultado ineficaces.

En la exploración, este varón de fototipo III, con daño actínico por exposiciones repetidas al sol, presentaba una discreta cicatriz hipocrómica como consecuencia de la electrocoagulación de una lesión, probablemente una queratosis actínica. En la simple inspección, resultaba evidente la retrocesión de la línea de implantación del cabello, con conservación en el resto del cuero cabelludo de una cantidad más que aceptable del mismo.

Igualmente presentaba en ambas cejas una pérdida de pelo acusada, con áreas alopécicas con un aspecto cicatricial (figs. 1 y 2). No observamos afectación de las mucosas ni las uñas y las demás áreas pilosas del cuerpo estaban conservadas.

No había antecedentes patológicos personales de importancia ni al parecer antecedentes familiares de alopecia androgénica.

La analítica de rutina, incluida la prueba serológica para la sífilis (VDRL) y la búsqueda de anticuerpos antinucleares (ANA), fue normal, salvo una discreta hipercolesterolemia.

Ante el aspecto cicatricial de la alopecia, decidimos practicar un estudio histopatológico de la misma, realizando dos biopsias punch de $4 \mathrm{~mm}$ para su sección longitudinal y transversal. Las imágenes estudiadas (fig. 3) mostraron un infiltrado inflamatorio linfohistiocitario perifolicular, con discreto depósito de 
\begin{tabular}{l|l} 
mi paciente es... & $\begin{array}{l}\text { Un varón con una alopecia frontal fibrosante: } \\
\text { ¿una entidad únicamente femenina? }\end{array}$
\end{tabular}

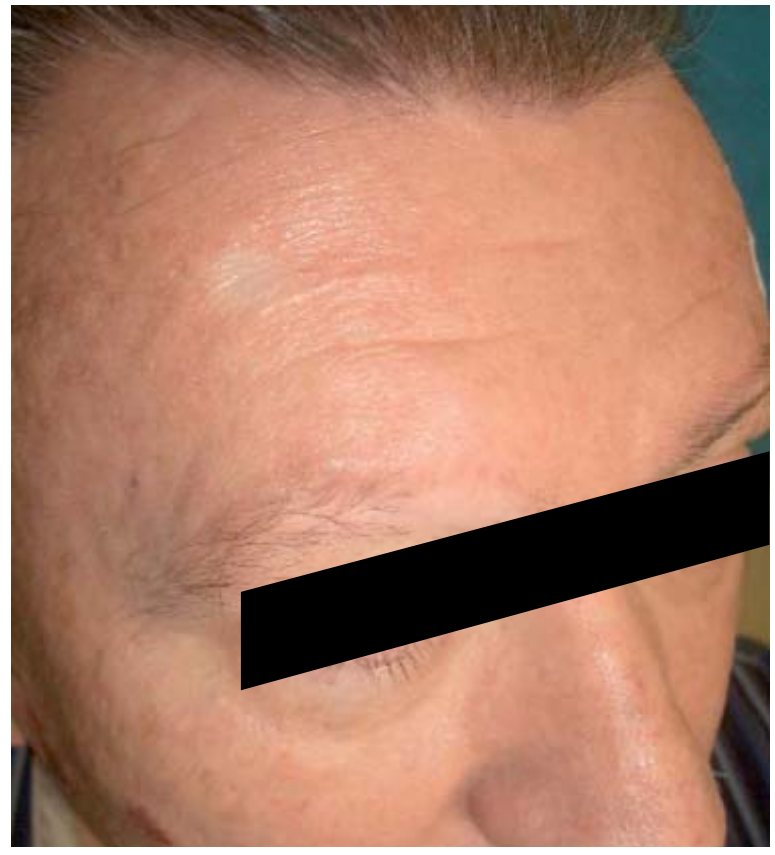

Figura 1. Afectación frontoparietal y de las cejas.

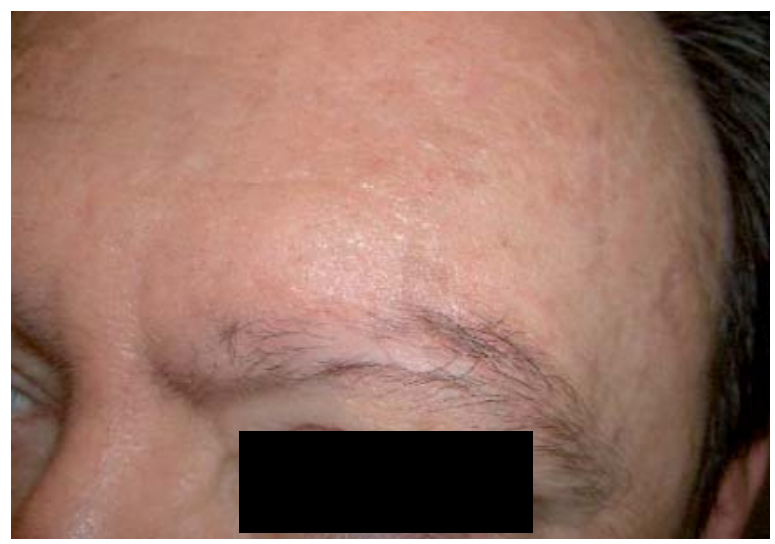

Figura 2. Evidente afectación de las cejas.

mucina en la dermis superficial. Se observaba igualmente un daño actínico añadido.

Diagnosticamos al paciente de alopecia frontal fibrosante e iniciamos el tratamiento con infiltraciones de triamcinolona, antimaláricos (sulfato de hidroxicloroquina, Dolquine ${ }^{\circledR}$ ) y una fórmula tópica que contenía alfa-tocoferol, triamci-

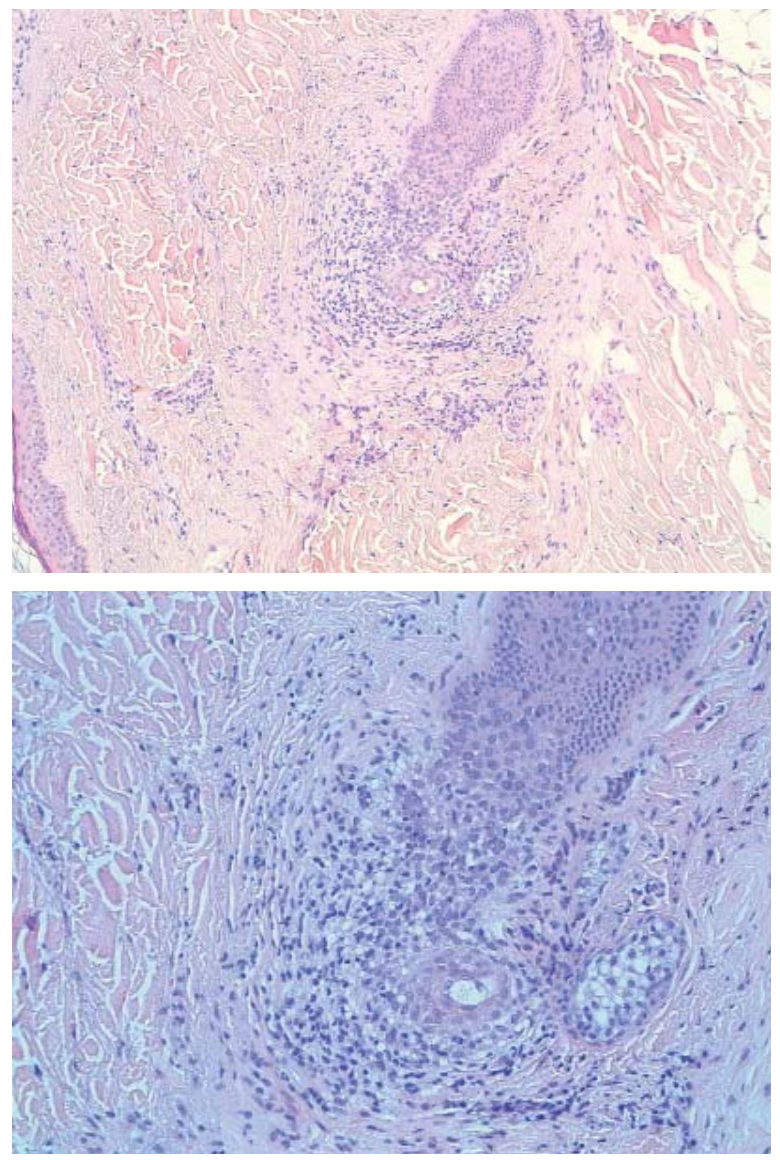

Figura 3. Infiltrado inflamatorio linfohistiocitario perifolicular. Discreto depósito de mucina en el dermis superficial.

nolona y minoxidil para el cuero cabelludo y corticoterapia tópica para las cejas.

Estamos controlando al paciente mensualmente desde hace 2 años y no hemos observado empeoramiento de su proceso.

La alopecia frontal fibrosante fue descrita por Kossard en $1994^{1}$, como una variante de alopecia cicatricial que afectaba a la zona frontoparietal de mujeres posmenopáusicas, con cambios cicatriciales en la superficie alopécica y presencia de alopecia en otras localizaciones, como las cejas. Habitualmente, se presenta en mujeres posmenopáusicas. Kossard describe en 1994 el caso de 16 pacientes, con una edad media de 68 años. En 2007, el Grupo de Tricología de la Academia Española de Dermatología de Sevilla publicó un 
trabajo que recogía los casos de 58 mujeres, con una edad media de 53 años².

Su etiología permanece incierta e histológicamente se superpone al liquen plano pilar, del que se considera una variante generalizada.

Clínicamente, existe una recesión de la línea de implantación del pelo y puede haber alopecia de las cejas, pero no se observan signos de liquen plano en localizaciones como uñas o mucosas ${ }^{3,4}$.

Con la técnica dermatoscópica, se observa una ausencia de aperturas foliculares en todos los pacientes e hiperqueratosis y eritema perifolicular en la mayoría de ellos. En el estudio histopatológico, se suelen encontrar hallazgos tales como una disminución del número de folículos y fibrosis perifolicular e infiltrado linfocitario de patrón liquenoide ${ }^{5}$. Los datos histopatológicos son similares en cuero cabelludo y cejas.

Los tratamientos referidos en la literatura son poco eficaces $^{6,7}$.

Desde su descripción, hemos recogido en nuestra Unidad de Tricología de Alicante más de 105 casos (lo que supone el 0,15\% de las alopecias femeninas vistas desde la descripción del cuadro), varios de ellos pertenecientes a miembros de una misma familia (madre e hija) y, hasta el caso que presentamos, únicamente en mujeres (en estos momentos, tenemos diagnosticados clínicamente, con confirmación biópsica, 2 casos más en varones, considerando que este problema debe existir desde hace tiempo pero no se había considerado esta posibilidad diagnóstica en el varón).

Sometemos a su consideración el caso de un varón que, tanto por la clínica como por la exploración e histopatología, padece una alopecia frontal fibrosante.

\section{BIBLIOGRAFÍA}

1. Kossard S. Postmenopausal frontal scarring alopecia. Scarring alopecia in a pattern distribution. Arch Derm. 1994;13:770-4.

2. Rodríguez Pichardo A. Alopecia frontal. Comunicación presentada en la XXII Reunión GEDCT, Granada oct. 2010.

3. Guerra Tapia A, Rodríguez Peralto JL, González Guerra E. Alopecia cicatricial en zona frontotemporal de cuero cabelludo (Alopecia fibrosante frontal postmenopáusica). Act Dermatolog. 2003;10:617-19.

4. Guerra Tapia A. La alopecia de la mujer. Madrid: Editorial Raíz Publicidad S.L.; 2009.

5. Chew AL, Bashir SJ, Wain EM, Fenton DA, Stefanato CM. Expanding the spectrum of frontal fibrosing alopecia: a unifying concept. J Am Acad Dermatol. 2010;63:653-60.

6. Georgala S, Katoulis AC, Befon A, Danopoulou I, Georgala C. Treatment of postmenopausal frontal fibrosing alopecia with oral dutasteride. J Am Acad Dermatol. 2009;61;157-8.

7. Moreno-Ramírez D, Ferrándiz L, Camacho FM. Alopecia frontal fibrosante. Valoración diagnóstica y terapéutica. Actas Dermosifilograf. 2007;98(9):594-602. 